This is an electronic reprint of the original article. This reprint may differ from the original in pagination and typographic detail.

Author(s): Salmi, Leo; Heikkilä, Mikko; Vehkamäki, Marko; Puukilainen, Esa; Ritala, Mikko; Sajavaara, Timo

Title: $\quad$ Studies on atomic layer deposition of IRMOF-8 thin films

Year: $\quad 2015$

Version:

Please cite the original version:

Salmi, L., Heikkilä, M., Vehkamäki, M., Puukilainen, E., Ritala, M., \& Sajavaara, T. (2015). Studies on atomic layer deposition of IRMOF-8 thin films. Journal of Vacuum Science and Technology A, 33(1), Article 01A121. https://doi.org/10.1116/1.4901455

All material supplied via JYX is protected by copyright and other intellectual property rights, and duplication or sale of all or part of any of the repository collections is not permitted, except that material may be duplicated by you for your research use or educational purposes in electronic or print form. You must obtain permission for any other use. Electronic or print copies may not be offered, whether for sale or otherwise to anyone who is not an authorised user. 


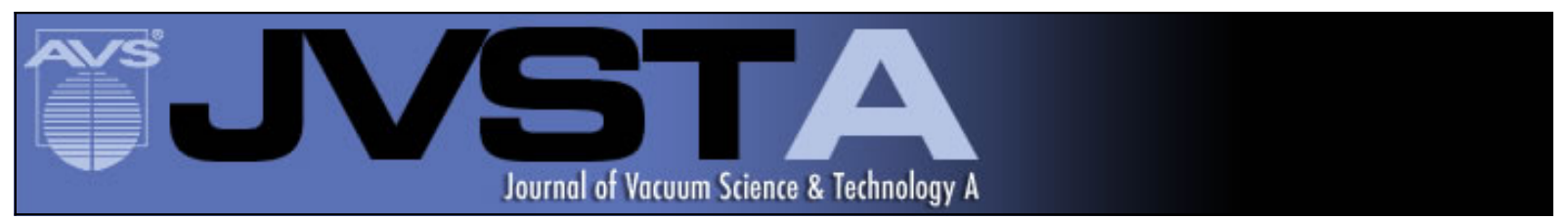

\section{Studies on atomic layer deposition of IRMOF-8 thin films}

Leo D. Salmi, Mikko J. Heikkilä, Marko Vehkamäki, Esa Puukilainen, Mikko Ritala, and Timo Sajavaara

Citation: Journal of Vacuum Science \& Technology A 33, 01A121 (2015); doi: 10.1116/1.4901455

View online: http://dx.doi.org/10.1116/1.4901455

View Table of Contents: http://scitation.aip.org/content/avs/journal/jvsta/33/1?ver=pdfcov

Published by the AVS: Science \& Technology of Materials, Interfaces, and Processing

\section{Articles you may be interested in}

Low-temperature atomic layer deposition of copper(II) oxide thin films

J. Vac. Sci. Technol. A 34, 01A109 (2016); 10.1116/1.4933089

Silicon oxynitride films deposited by reactive high power impulse magnetron sputtering using nitrous oxide as a single-source precursor

J. Vac. Sci. Technol. A 33, 05E121 (2015); 10.1116/1.4927493

Nucleation and growth of $\mathrm{ZnO}$ on PMMA by low-temperature atomic layer deposition

J. Vac. Sci. Technol. A 33, 01A128 (2015); 10.1116/1.4902326

Low temperature silicon dioxide by thermal atomic layer deposition: Investigation of material properties

J. Appl. Phys. 107, 064314 (2010); 10.1063/1.3327430

The impact of the density and type of reactive sites on the characteristics of the atomic layer deposited W N $\mathrm{C}$ y films

J. Appl. Phys. 99, 063515 (2006); 10.1063/1.2182074

\section{HDDEN}

\section{Instruments for Advanced Science}

w www.HidenAnalytical.com E info@hiden.co.uk

CLICK TO VIEW our product catalogue

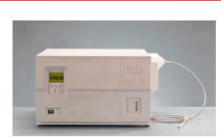

Gas Analysis

dynamic measurement of reaction gas streams catalysis and thermal analysis molecular beam studies

secies probes

fermentation, environmental and eccogical studies

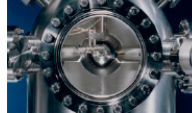

Surface Science

UHVTPD

SIMS emental imaging - surface mapping

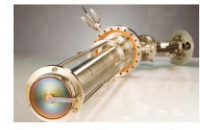

Plasma Diagnostics plasma source characterization etch and deposition process reaction

, analysis of neutral and radical species

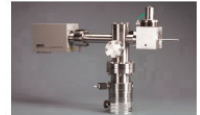

Vacuum Analysis partial pressure measurement and control of process gases reactive sputter process control vacuum diagnostics (n) 


\title{
Studies on atomic layer deposition of IRMOF-8 thin films
}

\author{
Leo D. Salmi, ${ }^{\text {a) }}$ Mikko J. Heikkilä, Marko Vehkamäki, Esa Puukilainen, and Mikko Ritala \\ Laboratory of Inorganic Chemistry, Department of Chemistry, University of Helsinki, P.O. Box 55, \\ 00014 Helsinki, Finland
}

\author{
Timo Sajavaara \\ Accelerator Laboratory, Department of Physics, University of Jyväskylä, P.O. Box 35, 40014 Jyväskylä, \\ Finland
}

(Received 18 August 2014; accepted 31 October 2014; published 11 November 2014)

\begin{abstract}
Deposition of IRMOF-8 thin films by atomic layer deposition was studied at $260-320^{\circ} \mathrm{C}$. Zinc acetate and 2,6-naphthalenedicarboxylic acid were used as the precursors. The as-deposited amorphous films were crystallized in $70 \%$ relative humidity at room temperature resulting in an unknown phase with a large unit cell. An autoclave with dimethylformamide as the solvent was used to recrystallize the films into IRMOF-8 as confirmed by grazing incidence x-ray diffraction. The films were further characterized by high temperature x-ray diffraction (HTXRD), field emission scanning electron microscopy, Fourier transform infrared spectroscopy (FTIR), time-of-flight elastic recoil detection analysis (TOF-ERDA), nanoindentation, and energy-dispersive x-ray spectroscopy. HTXRD measurements revealed similar behavior to bulk IRMOF-8. According to TOFERDA and FTIR, composition of the films was similar to IRMOF-8. Through-porosity was confirmed by loading the films with palladium using $\operatorname{Pd}(\text { thd })_{2}$ (thd =2,2,6,6-tetramethyl-3, 5-heptanedionato) as the precursor. (C) 2014 American Vacuum Society.

[http://dx.doi.org/10.1116/1.4901455]
\end{abstract}

\section{INTRODUCTION}

Metal-organic frameworks (MOFs) are hybrid materials consisting of metal ions or metal oxide clusters connected with rigid organic linker molecules. These structures result in the highest porosity found in any known material, including zeolites. Furthermore, the pore size and chemical environment in the pores are tunable by carefully choosing the linker molecule. Due to these exceptional attributes metal-organic frameworks are potential materials for gas storage, catalysis, drug release, chemical separation, and gas sensing. ${ }^{1-6}$ The most common method for synthetizing MOFs in the bulk form has been solvothermal growth in mother solution containing the precursors. ${ }^{1,7}$ However, depositing MOFs in thin film form creates new challenges for the growth methods. Thin films could open up new application areas for MOFs, including electronics, magnetics, and optics.

Several approaches for the MOF thin film deposition have been studied recently. These include solvothermal and microwave induced deposition from mother solution, gel-layer deposition, electrochemical deposition, and layerby-layer growth from solution. ${ }^{8-13}$ Although good-quality and continuous films have been achieved, most of these methods rely heavily on the selection of substrate materials or pretreatment of the surface. Usually, the surface must be activated by a suitable self-assembled monolayer or seed crystals of the desired MOF. Otherwise, the film can have poor adhesion to the substrate or the growth may be inhibited completely.

Atomic layer deposition (ALD) is an advanced vapor phase thin film deposition method. ${ }^{14}$ It is based on alternate

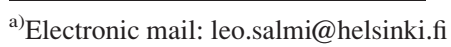

gaseous precursor exposures separated by inert gas purging. This results in self-limiting growth mechanism leading to large-area uniformity, good control over film composition, and superior conformality even on complicated 3D structures. In the recent years, molecular layer deposition (MLD), a special modification of ALD, has attracted wide attention. In MLD, layers of whole molecules are deposited during one self-limiting reaction step instead of atoms. A wide range of polymers and hybrid-materials have been deposited utilizing MLD, including polyimides, ${ }^{15}$ polyamides, ${ }^{16,17}$ alucones, ${ }^{18,19}$ zincones, ${ }^{19,20}$ and hybrid nanolaminates. ${ }^{21}$

The series of isoreticular MOFs (IRMOF) is a classic example of MOFs. ${ }^{1}$ It consists of cubic $\mathrm{Zn}_{4} \mathrm{O}$ (carboxylate) 6 compounds that are all derived from one of the most studied MOFs, MOF-5 (IRMOF-1). In our earlier study, we have demonstrated the deposition of MOF-5 thin films by combining ALD and a two-step postdeposition crystallization process. $^{22}$ The as-deposited amorphous films were first crystallized in moist air. This unknown phase was then recrystallized into the desired MOF-5 phase in an autoclave using dimethylformamide (DMF) as the solvent. In this work, the same concept has been utilized to deposit IRMOF8 thin films proving that the method can be used for other MOF thin films as well.

\section{EXPERIMENT}

\section{A. Film deposition}

IRMOF-8 thin films were deposited at $260-320^{\circ} \mathrm{C}$ in a hot-wall, flow-type F-120 ALD reactor (ASM Microchemistry Ltd., Helsinki, Finland). Zinc acetate $\left(\mathrm{ZnAc}_{2}\right)$ (Merck, $\geq 99.5 \%$ ) and 2,6-naphthalenedicarboxylic acid (2,6-NDC) (Aldrich, 99\%) (Fig. 1) were used as the precursors evaporated 


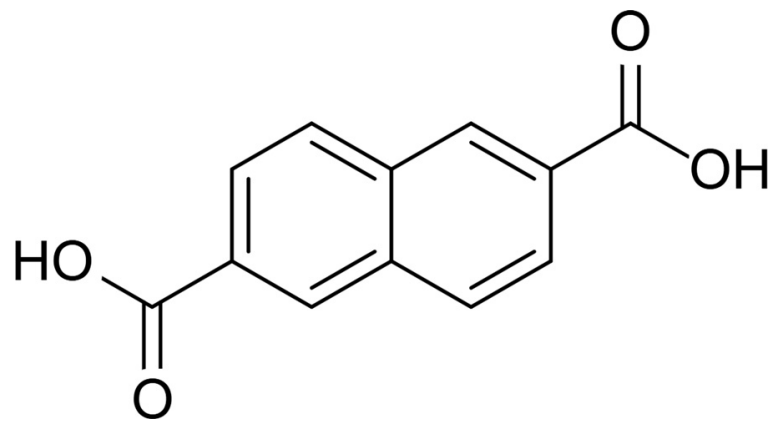

FIG. 1. 2,6-naphthalenedicarboxylic acid.

at 190 and $250^{\circ} \mathrm{C}$ inside the reactor. The pulse times were 0.5-3.0s for $\mathrm{ZnAc}_{2}$ and 0.5-3.0 s for 2,6-NDC. The purge time was $2.0-3.0 \mathrm{~s} .5 \times 5 \mathrm{~cm} \mathrm{Si}(100)$ and $1 \times 2 \mathrm{~cm} \mathrm{Si}(100)$ with trenches were used as the substrates. The carrier and purging gas was nitrogen (99.999\%, Labgas NG 2L), and the pressure inside the reactor $\sim 0.7 \mathrm{kPa}$. The as-deposited amorphous films were crystallized at room temperature in air at the relative humidity of $70 \%$ and recrystallized in an autoclave (Parr 4744) using $15 \mathrm{ml}$ of DMF as the solvent at $150{ }^{\circ} \mathrm{C}$ for $2 \mathrm{~h}$. The ALD process and crystallization in the autoclave was duplicated on the crystalline films in order to obtain continuous films.

\section{B. Characterization}

Thicknesses and refractive indices of the thin films were obtained from optical reflectance spectra measured with a Hitachi U2000 spectrophotometer $(\lambda=370-1100 \mathrm{~nm})$ and analyzed using a fitting program developed by Ylilammi and Ranta-aho. ${ }^{23}$ Field emission scanning electron microscopy (FESEM) images were taken with a Hitachi S-4800 FESEM using acceleration voltages of $10.0-15.0 \mathrm{kV}$.

Grazing incidence $\mathrm{x}$-ray diffraction (GIXRD) patterns were measured using a Panalytical X'Pert Pro MPD diffractometer. For the high-temperature $\mathrm{X}$-ray diffraction (HTXRD), an Anton Paar HTK-1200N oven-chamber was attached to the diffractometer. The measurements were done in air and $\mathrm{N}_{2}$ (Aga 99.999\%, further purified with Entegris $35 \mathrm{KF}-\mathrm{I}-4 \mathrm{R}$ purifier) in the temperature range of $25-450{ }^{\circ} \mathrm{C}$. Incident angle of $2^{\circ}$ was used in all measurements.

Fourier transform infrared spectroscopy (FTIR) and timeof-flight elastic recoil detection analysis (TOF-ERDA) were used to study the composition of the films. FTIR measurements were carried out with a PerkinElmer Spectrum GX FTIR system on samples deposited on $\mathrm{Si}(100) .30 \mathrm{~nm}$ of ALD $\mathrm{Al}_{2} \mathrm{O}_{3}$ was deposited on samples subjected to TOF-ERDA to protect the film under the ion beam. The $\mathrm{Al}\left(\mathrm{CH}_{3}\right)_{3}$ and $\mathrm{H}_{2} \mathrm{O}$ ALD process was used for this at $200^{\circ} \mathrm{C}$. TOF-ERDA analyses were done using $8.52 \mathrm{MeV}{ }^{35} \mathrm{Cl}^{5+}$ beam from a $1.7 \mathrm{MV}$ Pelletron accelerator in the Accelerator Laboratory of University of Jyväskylä.

MultiMode $\mathrm{V}$ atomic force microscope (AFM) equipped with a NanoScope V controller (Bruker) was used for qualitative nanoindentations. Nanoindentations were made with a diamond-tipped probe delivered by Bruker. Films were indented with trigger threshold values of $0.10-0.30 \mathrm{~V}$ with an indentation rate of $1.0 \mathrm{~Hz}$, and no hold time was set to peak load.

The vapor phase loading of the porous IRMOF-8 films with $\mathrm{Pd}(\text { thd })_{2}$ (thd = 2,2,6,6-tetramethyl-3,5-heptanedionato) (ABCR, 98\%) was carried out in a Schlenk bottle. The samples were placed in the bottle with the solid $\mathrm{Pd}(\text { thd })_{2}$ precursor and the system was pumped into a vacuum. To evaporate the precursor, the bottle was kept at $120^{\circ} \mathrm{C}$ for $24 \mathrm{~h}$. $\mathrm{Pd}$ (thd $)_{2}$ was then decomposed to metallic $\mathrm{Pd}$ at $200^{\circ} \mathrm{C}$ for 5 h. A FEI Quanta 3D 200i FIB-SEM fitted with an Oxford Instrument Inca 350 energy-dispersive $\mathrm{X}$-ray spectroscopy (EDS) system was used for cross section lamella lift-out and EDS measurements of the Pd loaded films. A $10 \mathrm{kV}$ electron probe was used for the $\mathrm{x}$-ray mapping.

\section{RESULTS AND DISCUSSION}

\section{A. Film growth}

The film growth was studied in the temperature range of 260-320 ${ }^{\circ} \mathrm{C}$. $260^{\circ} \mathrm{C}$ was chosen as the lower limit to avoid condensation of 2,6-NDC that requires an evaporation temperature of $250{ }^{\circ} \mathrm{C}$. Even though no distinct ALD plateau was observed, the growth rate remained in the high range of 4.0-4.9 $\AA$ /cycle between 260 and $300^{\circ} \mathrm{C}$ (Fig. 2). At $320^{\circ} \mathrm{C}$, severe thickness profile started to appear in the films. This is probably due to the decomposition of 2,6-NDC. Further depositions for characterization were done at $260{ }^{\circ} \mathrm{C}$ because it resulted in the highest growth rate of $4.9 \AA$ /cycle. It must also be noted that the films deposited at the lowest possible temperature gave the best results in postdeposition crystallization.

The growth behavior was also explored by varying the pulse times of $\mathrm{ZnAc}_{2}$ and 2,6-NDC (Fig. 3). Saturation was achieved already with $0.5 \mathrm{~s}$ precursor pulses demonstrating the self-limiting characteristics of the deposition process.

\section{B. Crystallization}

The as-deposited films were amorphous. The crystallization of the as-deposited films was approached in a two-step

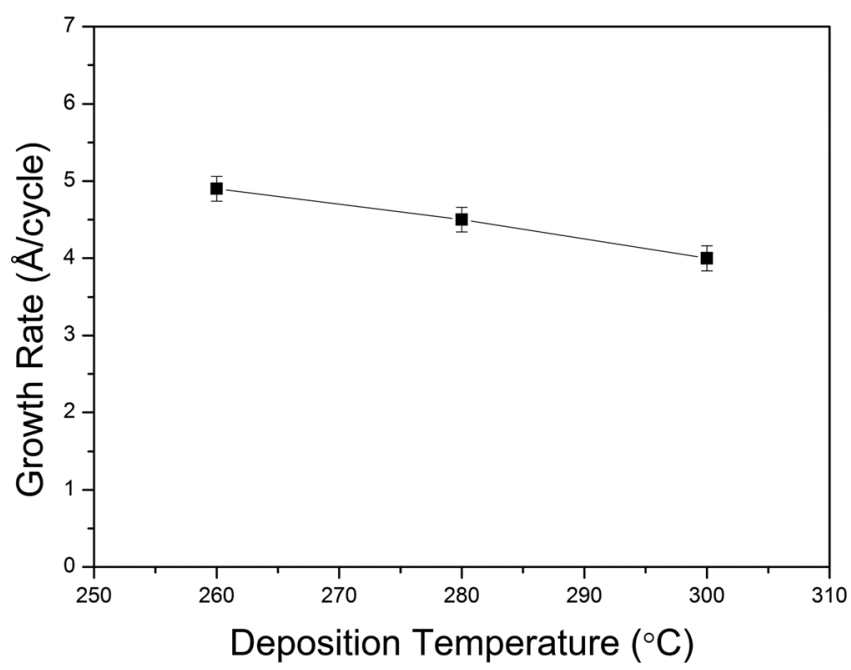

FIG. 2. Growth rate as a function of the deposition temperature. 

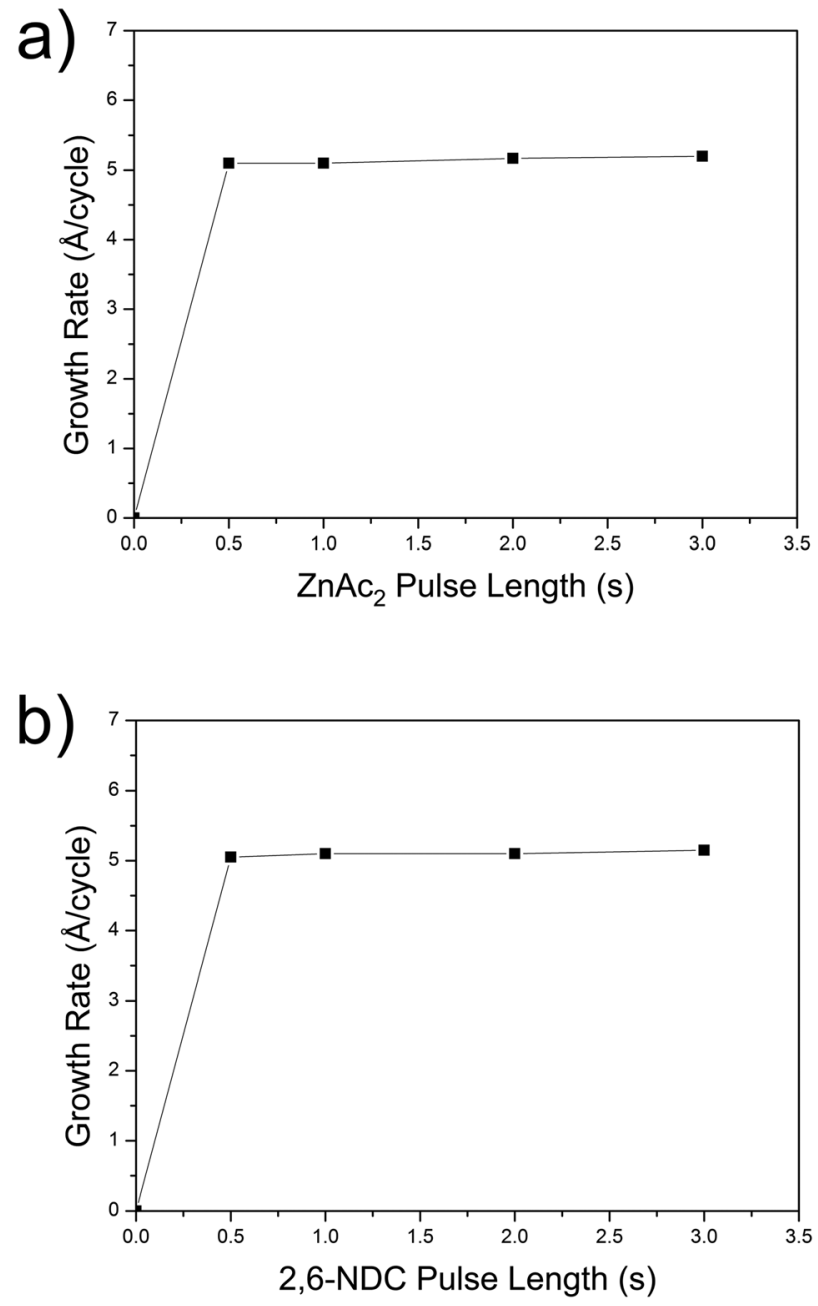

FIG. 3. Growth rate at $260^{\circ} \mathrm{C}$ as function of (a) $\mathrm{ZnAc}_{2}$ and (b) 2,6-NDC pulse length.

manner as in our earlier MOF-5 studies. ${ }^{22}$ The samples were placed in a humidity-controlled chamber for $24 \mathrm{~h}$ at room temperature. It was found out that these films needed a slightly higher humidity of $70 \%$ for crystallization compared to the MOF-5 films. After $24 \mathrm{~h}$, the crystallization was visible by optical microscope as the smooth film surface turned granular (Fig. 4). GIXRD showed a structure with a large unit cell (Fig. 5). None of the reflections matches to IRMOF8 or $\mathrm{ZnO}$. Therefore, similar to MOF-5 films, the phase crystallizing at this point appears to be unknown. The moisture crystallized phase was stable under $70 \%$ humidity as no change was seen in GIXRD after $96 \mathrm{~h}$.

HTXRD revealed a peak shift to higher $2 \theta$ values at $250{ }^{\circ} \mathrm{C}$ in the films crystallized in moist air (Fig. 6). A similar shift was also seen in the MOF-5 studies. ${ }^{22}$ The shift was permanent in $\mathrm{N}_{2}$ [Fig. 6(a)] and reversible in moist air [Fig. 6(b)]. This could support our proposal in the MOF-5 studies that the unknown phase is shrinking and expanding when moisture is leaving and re-entering the structure. Furthermore, the behavior could be related to breathing phenomenon known for flexible coordination polymers. ${ }^{24}$

DMF is a solvent commonly used in liquid phase synthesis of MOFs. ${ }^{1,7}$ In order to recrystallize the unknown phase

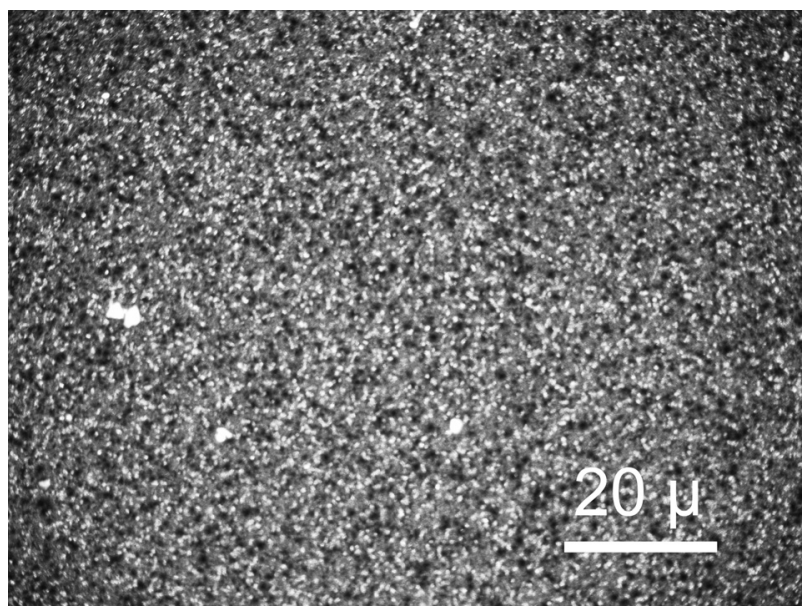

FIG. 4. Optical microscope image of a film crystallized in moist air.

into IRMOF-8, the films were placed in an autoclave with DMF. After $120 \mathrm{~min}$ at $150{ }^{\circ} \mathrm{C}$, GIXRD revealed a structure matching to IRMOF-8 (Fig. 7). The pattern is in good agreement with the theoretical pattern from the single crystal data and the results reported previously in literature for IRMOF8. ${ }^{1,25}$ The peak splitting observed around 8.2 and $13.1^{\circ} 2 \theta$ could be due to lattice defects such as interpenetrated networks and metal clusters in pores as reported by Wang et al. ${ }^{26}$ HTXRD showed an onset of decomposition to $\mathrm{ZnO}$ at $400{ }^{\circ} \mathrm{C}$ (Fig. 8), which is slightly lower than reported for bulk IRMOF-8. ${ }^{25}$ Attempts to crystallize the as-deposited films directly in DMF resulted in amorphous and noncontinuous films or complete dissolution of the film.

According to FESEM, the as-deposited films were smooth [Fig. 9(a)]. Image taken after the crystallization in moist air [Fig. 9(b)] showed a rough, continuous film. After the crystallization in DMF, continuity is lost as the IRMOF-8 crystals are formed [Fig. 9(c)]. Too low crystallization temperature resulted in amorphous or poorly crystalline films. At higher temperatures, the MOF started to dissolve leaving only some clusters on the substrate. In order to improve the continuity, the ALD process and crystallization in DMF was repeated on a crystallized IRMOF- 8 film. This resulted in a

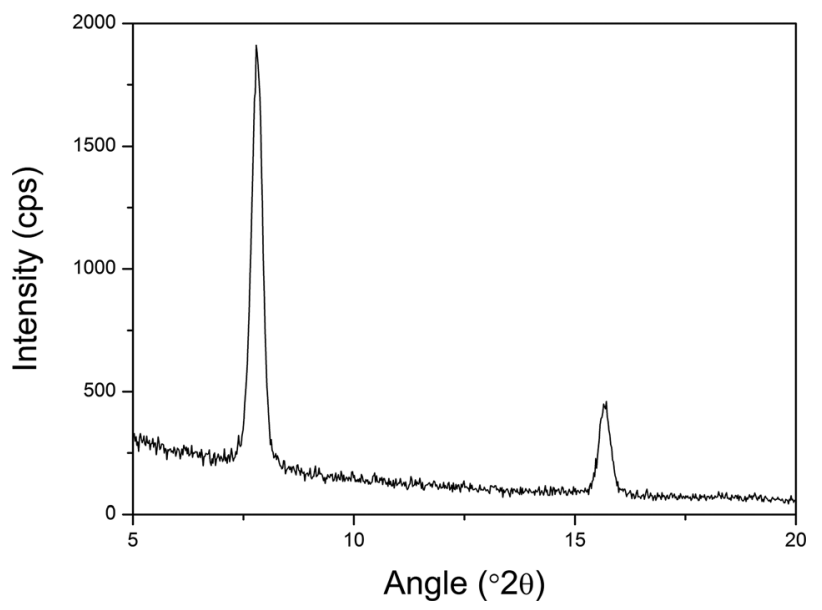

FIG. 5. GIXRD of a film crystallized in moist air. 

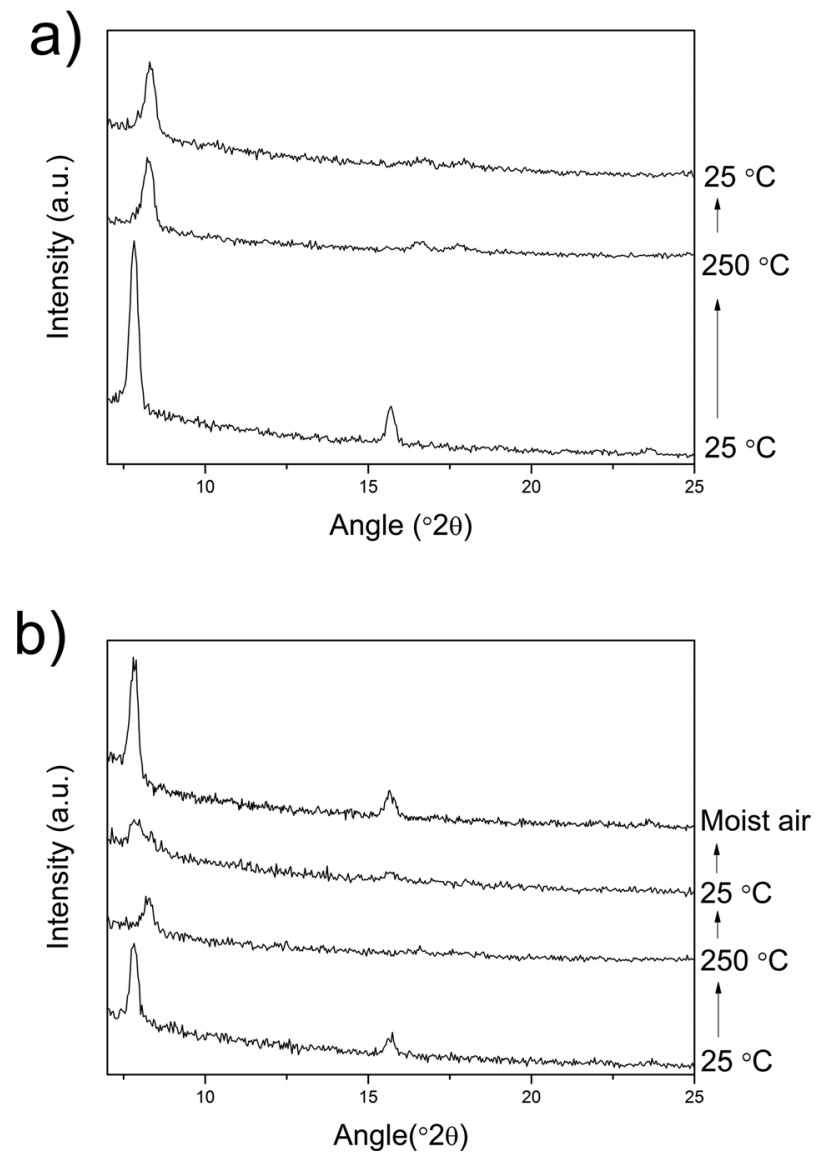

FIG. 6. HTXRD results of a film crystallized in moist air when heated up to $250^{\circ} \mathrm{C}$ and cooled back to $25^{\circ} \mathrm{C}$ in (a) $\mathrm{N}_{2}$ and (b) in air.

continuous film with good crystallinity [Fig. 9(d)]. Unlike in the ALD of MOF-5, ${ }^{22}$ the IRMOF- 8 crystals are clearly visible in the film, and no cracking of the film is observed.

For conformality testing, samples were deposited on a Si(100) substrate with trenches. The same deposition and crystallization parameters were used as on the flat $\mathrm{Si}(100)$ substrates. Cross-sectional FESEM samples were made by fracturing the substrate in halves. The film seems to be

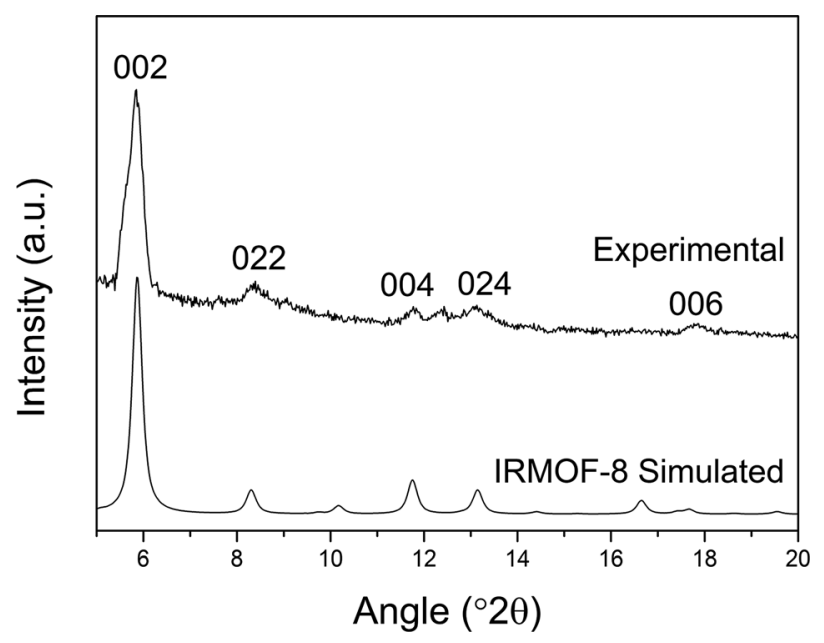

FIG. 7. GIXRD of a film crystallized in an autoclave with DMF as the solvent.

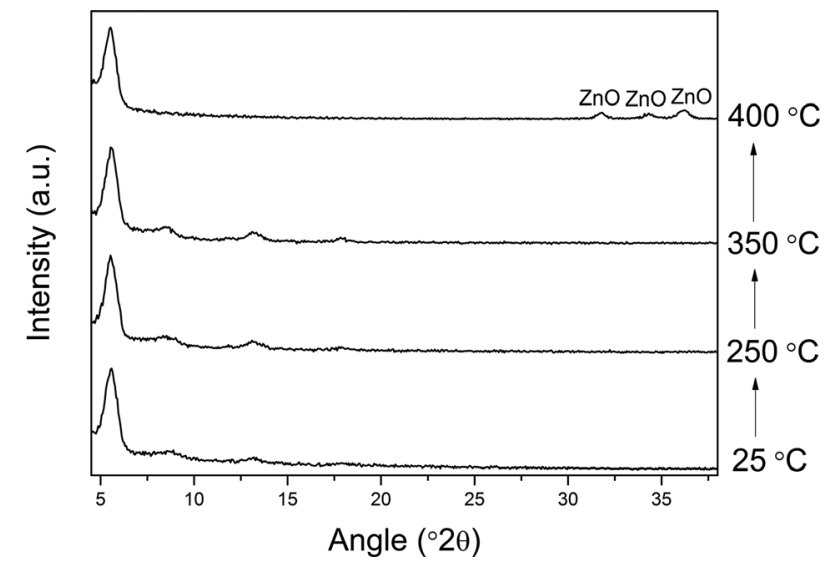

FIG. 8. HTXRD diffractograms of an IRMOF-8 film.

strongly attached to the substrate as no peeling off was observed (Fig. 10). A complete filling was achieved in the narrow trenches. In the wider trenches, the film is slightly thinner on the high-stress regions, but still relatively conformal.

\section{Film composition}

The FTIR spectrum of a crystallized IRMOF-8 film exhibits strong $\mathrm{COO}$ stretching vibration bands in the range of $1400-1700 \mathrm{~cm}^{-1}$ (Fig. 11). The weak band around $520 \mathrm{~cm}^{-1}$ can be assigned to $\mathrm{Zn}-\mathrm{O}$ stretching. Both features are characteristic for IR spectra measured earlier for MOFs in the IRMOF series. ${ }^{25,27}$ The broad band in the range of $3000-3500 \mathrm{~cm}^{-1}$ is probably originating from moisture adsorbed from air.

TOF-ERDA analysis of the IRMOF-8 films crystallized in an autoclave is complicated by their porosity and roughness. Therefore, TOF-ERDA was measured from a film crystallized in moist air (Fig. 12). The protective $\mathrm{Al}_{2} \mathrm{O}_{3}$ capping layer can be seen in the depth profile before the film itself. The measured elemental concentrations match closely to the calculated theoretical values in parenthesis.

\section{Nanoindentation}

Qualitative AFM based nanoindentation was done on $\sim 150 \mathrm{~nm}$ thick samples. A $\mathrm{ZnO}$ film deposited by ALD using diethyl zinc and water as the precursors at $250^{\circ} \mathrm{C}$ was compared to amorphous and moisture crystallized films. The IRMOF-8 films crystallized in DMF were too rough for the AFM based nanoindentation. The load versus displacement curves are presented in Fig. 13. Qualitative mechanical properties of the films can be evaluated using these curves. Elasticity correlates with the recovery during unloading $\left(\mathrm{h}_{\max }-\mathrm{h}_{\mathrm{f}}\right)$, softness with the maximum displacement, and plastic deformation with the area between the loading and unloading curves. It can clearly be seen that softness, elasticity, and plasticity are higher for the hybrid films compared to the bare $\mathrm{ZnO}$ film. This was expected because of the organic constituents in the hybrid films. While there is no substantial difference between the amorphous and crystalline phases, it seems that the amorphous phase has a slightly higher 

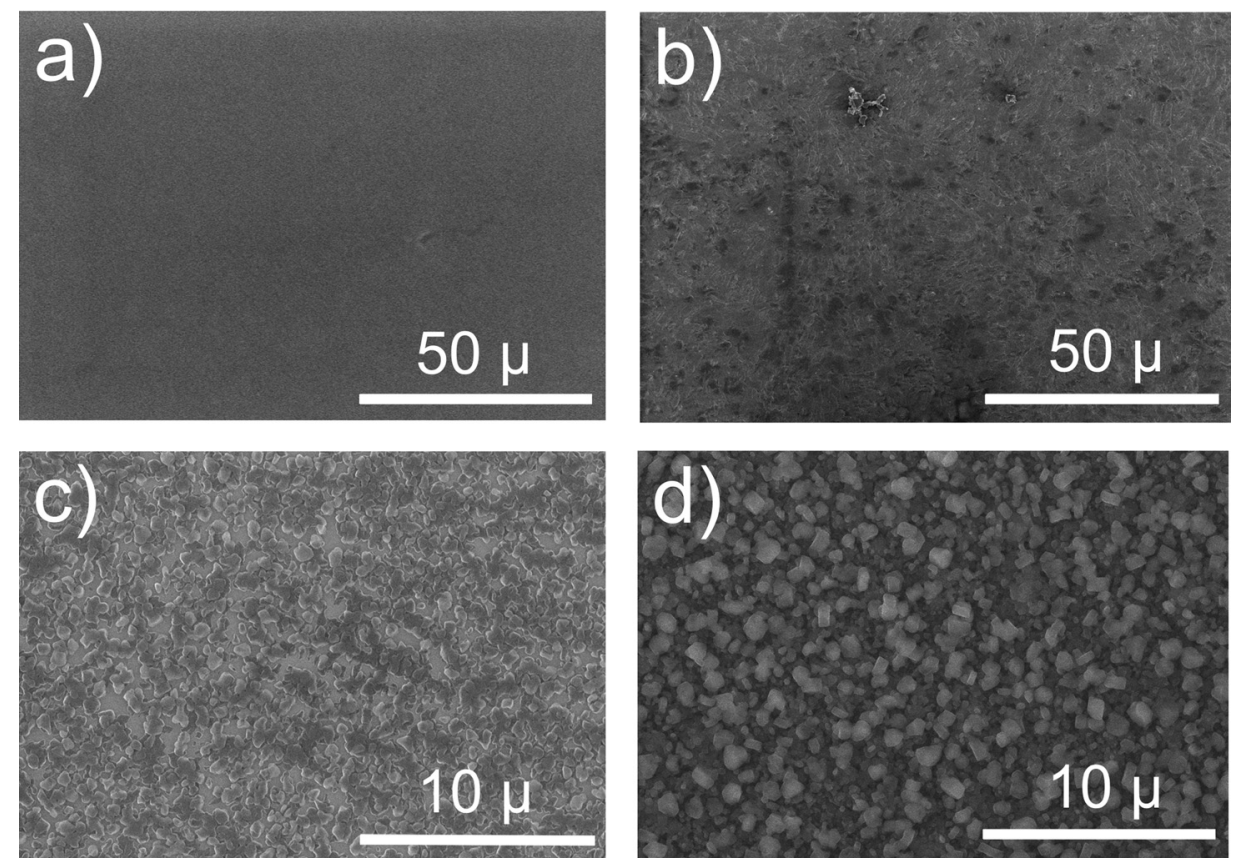

FIG. 9. FESEM images of a film (a) as-deposited (b) after the crystallization in moist air, (c) after the crystallization in an autoclave with DMF, and (d) after the second deposition and crystallization in DMF.
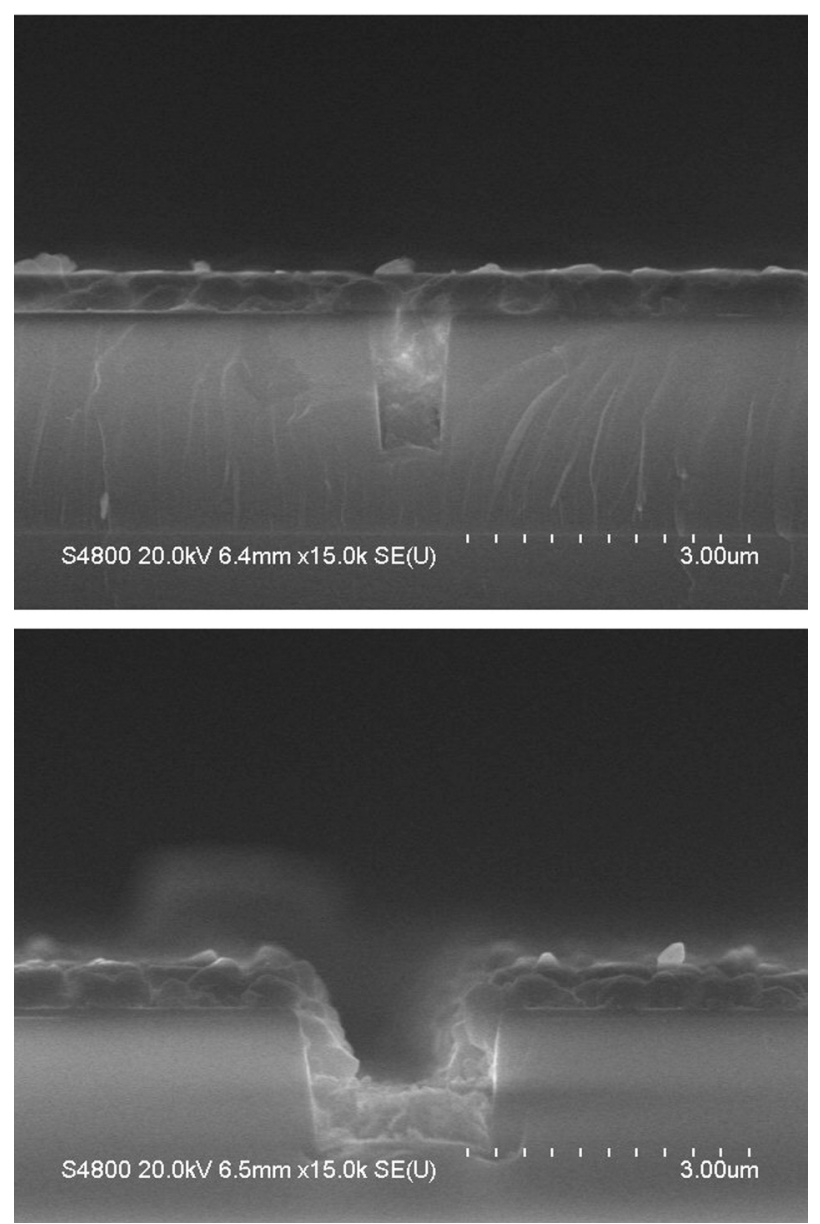

FIG. 10. Cross-sectional images of an IRMOF-8 film deposited on a $\mathrm{Si}(100)$ substrate with trenches. plasticity compared to the crystalline phase. It must be noted that the results are identical to the amorphous and films crystallized in moist air in our MOF-5 studies. ${ }^{22}$

\section{E. Loading of IRMOF-8 with Pd}

Pd loading has been previously reported for bulk MOF-5 and MOF-5 films using $\left[\mathrm{Pd}\left(\eta^{3}-\mathrm{C}_{3} \mathrm{H}_{5}\right)\left(\eta^{5}-\mathrm{C}_{5} \mathrm{H}_{5}\right)\right]$ as the precursor. $^{28,29}$ In this work, $\mathrm{Pd}(\text { thd })_{2}$ was used for the Pd loading of IRMOF-8 films as it is commercially available and evaporates at relatively low temperatures under vacuum. Additionally, IRMOF-8 has a larger pore window size compared to MOF-5, which should enable absorption of larger precursor molecules. The sample was first kept in a Schlenk bottle under vacuum at room temperature to remove possible

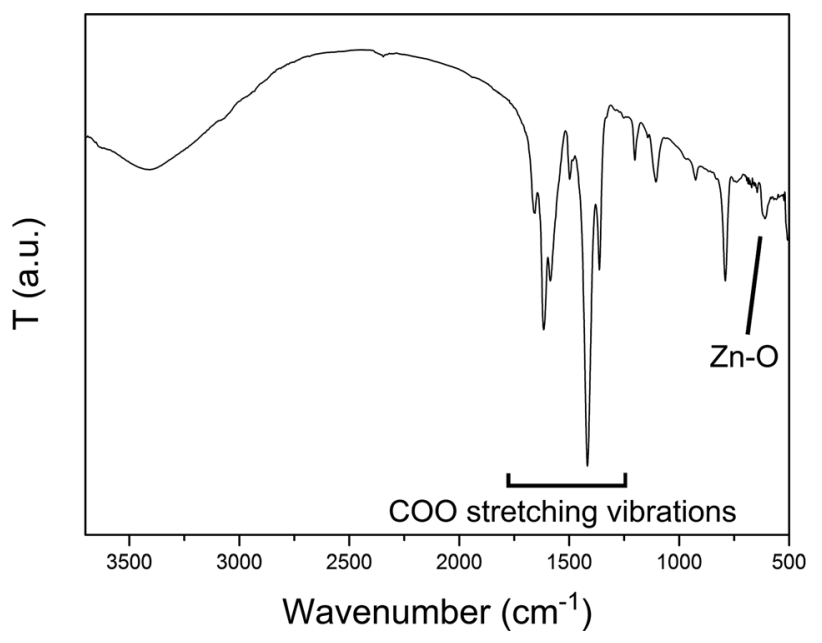

FIG. 11. FTIR spectrum of an IRMOF-8 film. 


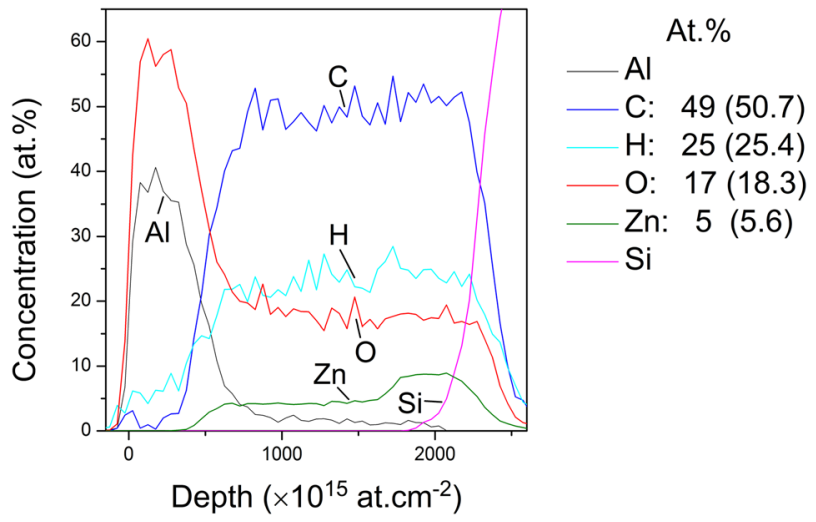

FIG. 12. (Color online) TOF-ERDA results of a film crystallized in moist air. The calculated theoretical atomic concentrations for bulk IRMOF-8 are given in the parenthesis. The $\mathrm{Zn}$ depth profile was determined by using scattered incident ${ }^{35} \mathrm{Cl}$ ions. The increase of $\mathrm{Zn}$ content near the interface is not real but due to scattering of ${ }^{35} \mathrm{Cl}$ from surface $\mathrm{Al}$ in addition to $\mathrm{Zn}$.

solvent residues from the pores. Next the temperature was elevated to $120^{\circ} \mathrm{C}$ for $24 \mathrm{~h}$ for loading of the precursor molecules into the IRMOF-8 film. Finally, the decomposition to $\mathrm{Pd}$ was done at $200{ }^{\circ} \mathrm{C}$ under vacuum. This was visible by the color change from white [Fig. 14(a)] to black [Fig. 14(b)]. The presence of metallic Pd was also confirmed by GIXRD (Fig. 15).

These results imply that even if $\operatorname{Pd}(\text { thd })_{2}$ is not expected to react with IRMOF-8, van der Waals interactions are strong enough to retain $\mathrm{Pd}(\text { thd })_{2}$ in the pores until its decomposition temperature is reached. A large size of the guest molecule in comparison to the MOF pore size is known beneficial in stabilizing the loaded structure. ${ }^{27}$

The penetration of $\mathrm{Pd}$ into the IRMOF-8 network through the whole film thickness was studied by EDS mapping a FIB-SEM lift-out lamella thinned to $\sim 500 \mathrm{~nm}$ thickness (Fig. 16). The EDS maps in Fig. 16 show that the signal from $\mathrm{Pd}$ is overlapping with the signals from $\mathrm{Zn}$ and $\mathrm{O}$. This indicates that $\mathrm{Pd}$ is uniformly spread in the IRMOF-8 film and does not reside only in the topmost parts of the film.

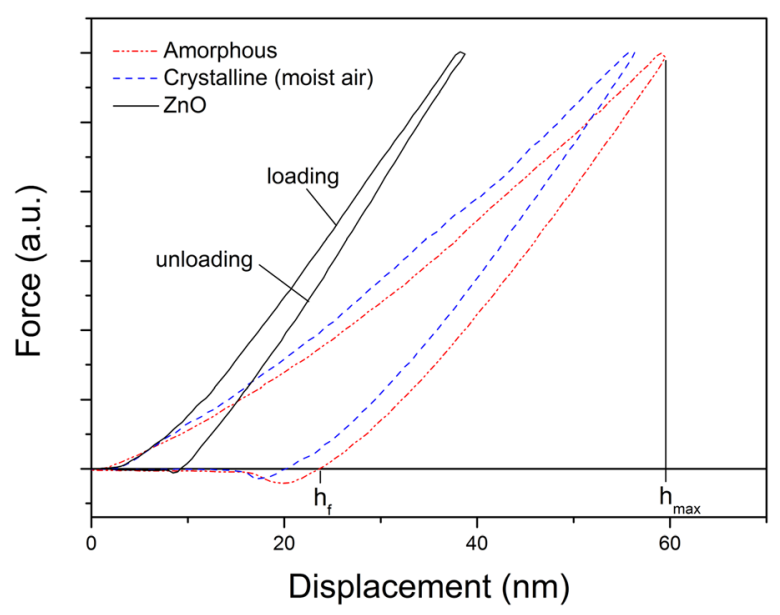

FIG. 13. (Color online) Nanoindentation curves for $\mathrm{ZnO}$, amorphous, and moisture crystallized films.
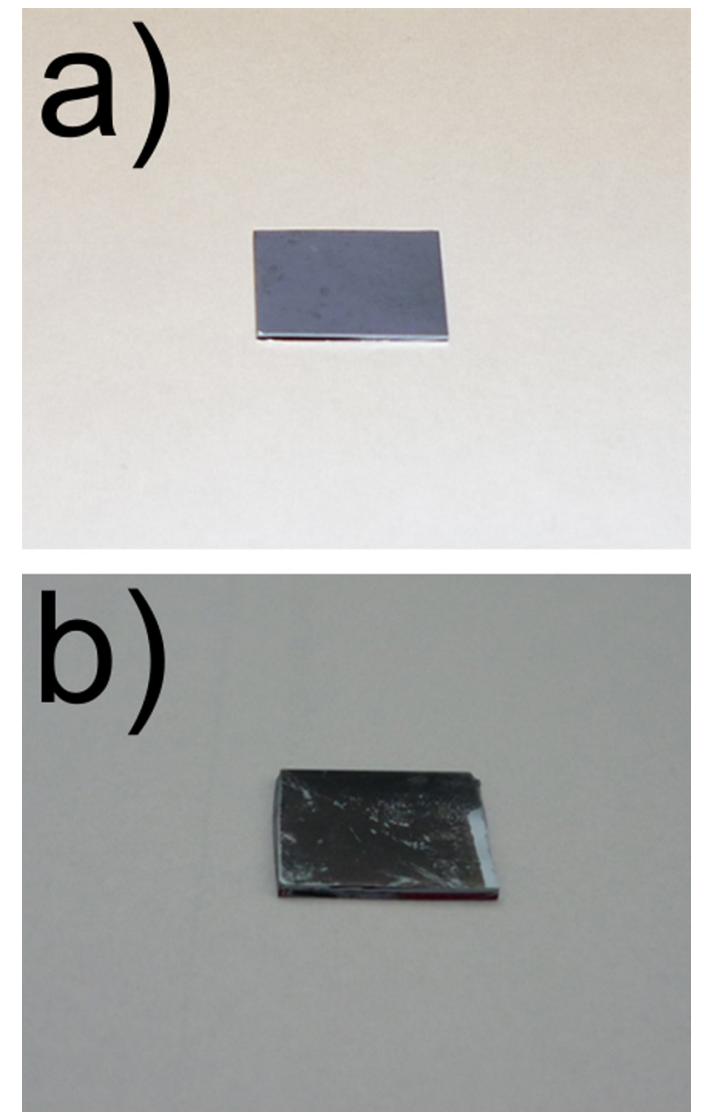

FIG. 14. (Color online) IRMOF-8 film (a) before the loading with Pd and (b) after the loading and decomposition to $\mathrm{Pd}$.

\section{SUMMARY AND CONCLUSIONS}

IRMOF-8 thin films were successfully deposited by using the combination of ALD and a two-step postdeposition crystallization process similar to that we have previously reported for MOF-5. ${ }^{22}$ Hybrid thin films were first deposited using $\mathrm{ZnAc}_{2}$ and 2,6-NDC as the precursors. The asdeposited amorphous films were crystallized in moist air resulting in an unknown structure. The final IRMOF-8 structure was obtained in an autoclave using DMF as the solvent at $150^{\circ} \mathrm{C}$. In order to improve the continuity of the

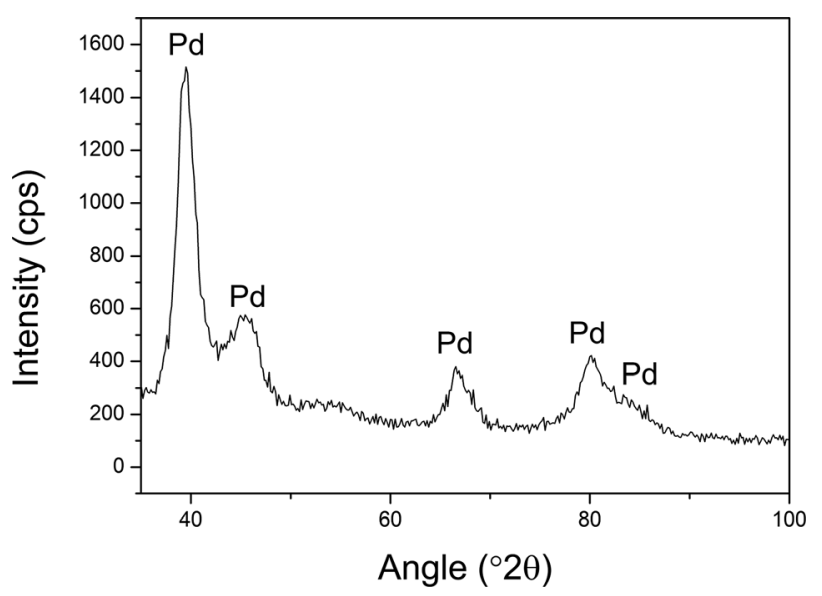

FIG. 15. GIXRD of an IRMOF-8 film loaded with Pd. 

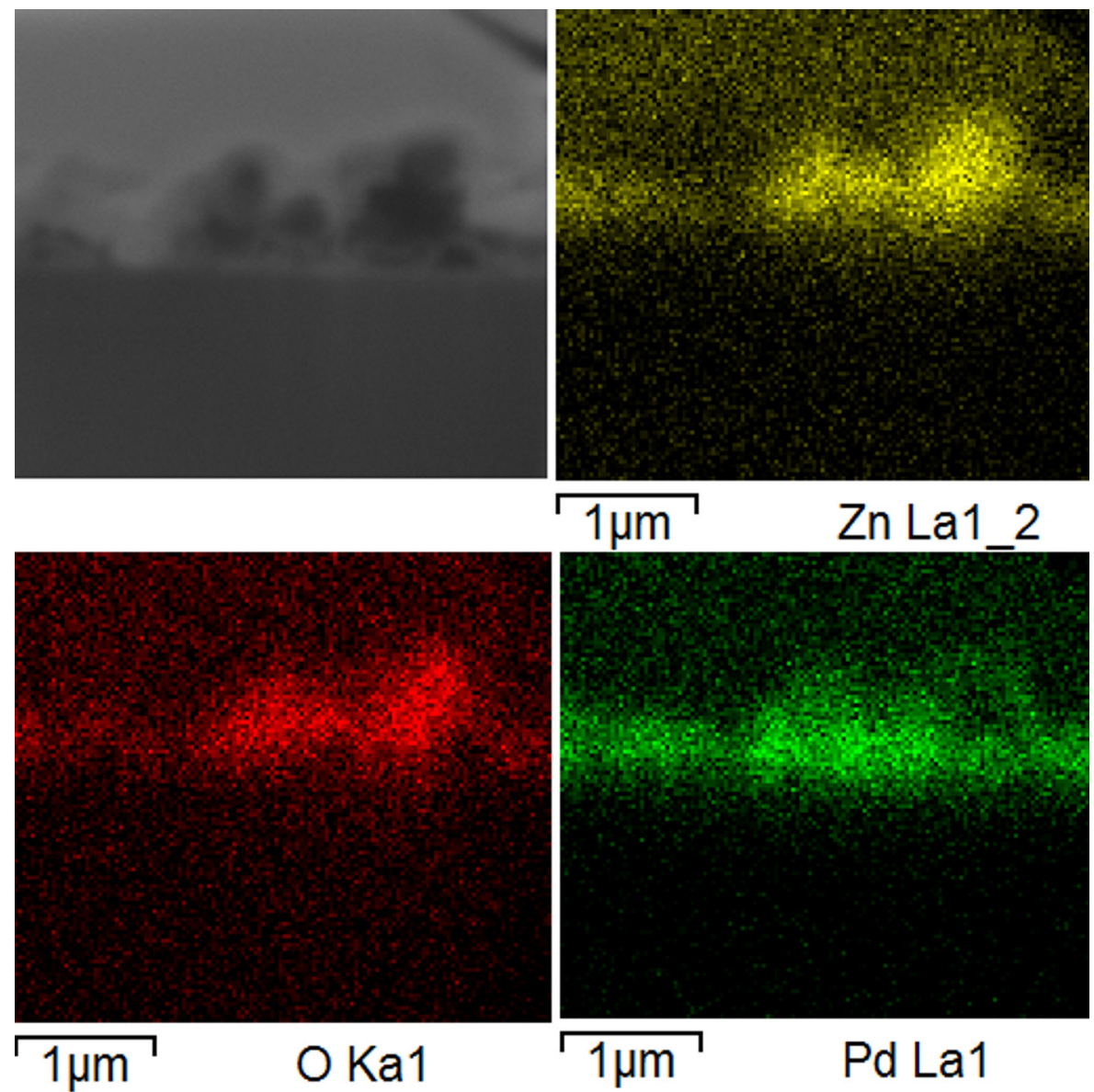

FIG. 16. (Color online) Cross-sectional EDS maps of an IRMOF-8 film loaded with Pd.

crystallized films, the film deposition and crystallization in DMF was repeated. Cross-sectional FESEM images revealed conformal IRMOF-8 films in trench structures. Pd loading of IRMOF-8 was carried out using $\mathrm{Pd}(\text { thd })_{2}$ as the precursor. Reflections of metallic Pd could be seen in GIXRD. EDS mapping of FIB cross-sectional samples showed that Pd was uniformly distributed throughout the film. Based on these results, we conclude that the combination of ALD and postdeposition crystallization first used for MOF-5 can be extended to other MOFs as well. Highly conformal MOF thin films can be deposited as long as precursors with suitably low evaporation temperatures are found.

\section{ACKNOWLEDGMENTS}

This work was funded by Academy of Finland Project No. 121325 and is linked to the Finnish Centre of Excellence in Atomic Layer Deposition and the Centre of Excellence in Nuclear and Accelerator Based Physics. The authors would like to thank Emma Salmi for her help with the FESEM.

\footnotetext{
${ }^{1}$ M. Eddaoudi, J. Kim, N. Rosi, D. Vodak, J. Wachter, M. O'Keeffe, and O. M. Yaghi, Science 295, 469 (2002).

${ }^{2}$ N. L. Rosi, J. Eckert, M. Eddaoudi, D. T. Vodak, J. Kim, M. O’Keeffe, and O. M. Yaghi, Science 300, 1127 (2003).

${ }^{3}$ S. Hermes, M. K. Schroter, R. Schmid, L. Khodeir, M. Muhler, A. Tissler, R. W. Fischer, and R. A. Fischer, Angew. Chem., Int. Ed. 44, 6237 (2005).
}

${ }^{4}$ P. Horcajada, C. Serre, G. Maurin, N. A. Ramsahye, F. Balas, M. ValletRegi, M. Sebban, F. Taulelle, and G. Ferey, J. Am. Chem. Soc. 130, 6774 (2008).

${ }^{5}$ Y. S. Li, F. Y. Liang, H. G. Bux, W. S. Yang, and J. Caro, J. Membr. Sci. 354, 48 (2010).

${ }^{6}$ G. Lu and J. T. Hupp, J. Am. Chem. Soc. 132, 7832 (2010).

${ }^{7}$ H. Fanø Clausen, R. Damgaard Poulsen, A. D. Bond, M.-A. S. Chevalier, and B. Brummerstedt Iversen, J. Solid State Chem. 178, 3342 (2005).

${ }^{8}$ Y. Yoo and H. K. Jeong, Chem. Commun. 21, 2441 (2008).

${ }^{9}$ Y. Yoo, Z. P. Lai, and H. K. Jeong, Microporous Mesoporous Mater. 123, 100 (2009).

${ }^{10}$ P. Horcajada, C. Serre, D. Grosso, C. Boissiere, S. Perruchas, C. Sanchez, and G. Ferey, Adv. Mater. 21, 1931 (2009).

${ }^{11}$ U. Müller, H. Pütter, M. Hesse, and H. Wessel, WO2005/049892 A1 (2 June 2005).

${ }^{12}$ U. Müller, H. Pütter, M. Hesse, M. Schubert, H. Wessel, J. Huff, and M. Guzmann, US2011/105776 A1 (5 May 2011).

${ }^{13}$ O. Shekhah et al., J. Am. Chem. Soc. 129, 15118 (2007).

${ }^{14}$ M. Ritala and J. Niinistö, Chemical Vapour Deposition: Precursors, Processes and Applications, edited by A. C. Jones and M. L. Hitchman (The Royal Society of Chemistry, Cambridge, U.K., 2009), pp. 158-206.

${ }^{15}$ M. Putkonen, J. Harjuoja, T. Sajavaara, and L. Niinistö, J. Mater. Chem. 17, 664 (2007).

${ }^{16}$ T. Yoshimura, S. Tasuura, and W. Sotoyama, Appl. Phys. Lett. 59, 482 (1991).

${ }^{17}$ H. I. Shao, S. Umemoto, T. Kikutani, and N. Okui, Polymer 38, 459 (1997).

${ }^{18}$ A. A. Dameron, D. Saghete, B. B. Burton, S. D. Davidson, A. S. Cavanagh, J. A. Bertand, and S. M. George, Chem. Mater. 20, 3315 (2008).

${ }^{19}$ O. Nilsen, K. B. Klepper, H. Ø. Nielsen, and H. Fjellvåg, ECS Trans. 16, 3 (2008).

${ }^{20}$ Q. Peng, B. Gong, R. M. VanGundy, and G. N. Parsons, Chem. Mater. 21, 820 (2009). 
${ }^{21}$ L. D. Salmi, E. Puukilainen, M. Vehkamäki, M. J. Heikkilä, and M. Ritala, Chem. Vap. Deposition 15, 221 (2009).

${ }^{22}$ L. D. Salmi, M. J. Heikkilä, E. Puukilainen, T. Sajavaara, D. Grosso, and M. Ritala, Microporous Mesoporous Mater. 182, 147 (2013).

${ }^{23}$ M. Ylilammi and T. Ranta-aho, Thin Solid Films 232, 56 (1993).

${ }^{24}$ K. Uemura, R. Matsuda, and S. Kitagawa, J. Solid State Chem. 178, 2420 (2005).

${ }^{25}$ L. T. L. Nguyen, C. V. Nguyen, G. H. Dang, K. K. A. Le, and N. T. S. Phan, J. Mol. Catal. A: Chem. 349, 28 (2011).
${ }^{26}$ C.-Y. Wang, C.-S. Tsao, M.-S. Yu, P.-Y. Liao, T.-Y. Chung, H.-C. Wu, M. A. Miller, and Y.-R. Tzeng, J. Alloys Compd. 492, 88 (2010).

${ }^{27}$ S. Hermes, F. Schröder, S. Amirjalayer, R. Schmid, and R. A. Fischer, J. Mater. Chem. 16, 2464 (2006).

${ }^{28}$ D. Esken, X. Zhang, O. I. Lebedev, F. Schröder, and R. A. Fischer, J. Mater. Chem. 19, 1314 (2009).

${ }^{29}$ S. Hermes, D. Zacher, A. Baunemann, C. Wöll, and R. A. Fischer, Chem. Mater. 19, 2168 (2007). 